\title{
UMA ANÁLISE dA REAÇÃO ESTÉTICA NA LEITURA D'A BOLSA AMARELA, DE LYGIA BOJUNGA NUNES
}

\author{
An analysis of the aesthetic reaction in the reading of $A$ Bolsa Amarela, by Lygia \\ Bojunga Nunes
}

\author{
Géssica Aparecida Cappoani \\ https://orcid.org/0000-0002-9821-1337 (1) \\ Universidade Tecnológica Federal do Paraná, Programa de Pós-Graduação em \\ Letras, Pato Branco, PR, Brasil. 85503-390 - ppgl-pb@utfpr.edu.br \\ Anselmo Pereira de Lima \\ https://orcid.org/0000-0003-1427-2165 (0) \\ Universidade Tecnológica Federal do Paraná, Programa de Pós-Graduação em \\ Letras, Pato Branco, PR, Brasil. 85503-390 - ppgl-pb@utfpr.edu.br
}

Resumo: O presente trabalho tem por objetivo analisar o desenvolvimento da personagem Raquel, bem como a reação estética provocada no leitor pela obra $A$ bolsa amarela, de Lygia Bojunga Nunes. A narrativa articula-se por meio das vontades da menina, que são o oposto da condição real que ela vivencia na família. Desse modo, constroem-se os dois cronotopos da narrativa: cronotopo da imaginação e cronotopo da realidade. Segundo Vygotsky (1999), em Psicologia da arte, na articulação da obra literária há sempre sentimentos opostos crescendo na mesma proporção, que se desenvolvem até o ponto culminante, no qual se fundem, como em um curto-circuito atingindo o efeito estético da arte, a catarse. Nesse sentido, a análise se desenvolve sobre mecanismos utilizados pela narradora da obra, tanto na construção dos cronotopos da imaginação e da realidade, quanto nos seus engendramentos na narrativa, visando compreender o desenvolvimento da narradora, bem como a catarse do leitor durante a leitura.

Palavras-chave: Desenvolvimento. Catarse. Literatura infantojuvenil.

Abstract: The present study aims to analyze Raquel character's development, at the same time analyzes the aesthetic reaction caused in the reader through the book $A$ bolsa amarela, by Lygia Bojunga Nunes. This narrative articulated itself through the girl desires, they are the opposite of her real condition in her family. Hence, it builds the two narrative's chronotope: imagination's chronotope and reality's chronotope. According to Vygotsky (1999), in Psychology of art, in the articulation of literary work, there are always opposite feelings growing up in the same proportion, this develops until the highest point, in which they fuse themselves, as a shot-circuit, reaching the aesthetic reaction of art, the catharsis. Thus, the analysis is developed about the mechanism used for the book narrator, as in the building of the imagination and reality's choronopes, as in the articulation of narrative, aiming to comprehend the narrator's development, as well as the reader's catharsis over the reading.

Keywords: Development. Catharsis. Young people literature.

\section{Introdução}

Obra representativa da literatura infantojuvenil brasileira, A bolsa amarela, de Lygia Bojunga Nunes (1976), tem como narradora a personagem protagonista do romance, Raquel. As relações e conflitos sociais são reconstruídos por meio do ponto de vista da 
menina. Sobre essa questão Maria Marlene Silva (2000) discute que a obra inova no que se refere à produção literária para crianças, visto que aborda uma temática que envolve o leitor, ao mesmo tempo que "centraliza a história na criança" (2000, p. 9).

Lygia Bojunga Nunes elabora uma obra na qual tanto os conflitos quanto a imaginação são interpretados e (re)criados por meio do filtro infantil. A autora brinca com a relação criativa entre a "liberdade do imaginário e a realidade" (RECHOU, 2010, p. 156). Sobre o estilo das obras de Lygia Bojunga Nunes, Carina Dartora Zonin (2008, p. 2) ressalta que é recorrente "a questão da realidade versus fantasia".

No caso d'A bolsa amarela, a trama narrada por Raquel a seu leitor, revela a situação da criança em um contexto desafiador: a ausência dos pais no cuidado com a criança, a pressão de ser a filha mais nova, a falta de espaço da criança na participação familiar e ainda de saber que veio de "araque" - esse termo é utilizado pela narradora se referindo ao fato de que nasceu sem que os pais a desejassem. Portanto, concorda-se com Silva (2000) em que A bolsa Amarela discute, justamente, "a falta de integração da criança à família" (2000, p. 9).

Do mesmo modo que na obra, na vida real uma parcela significativa de crianças sofre com situações adversas em seu seio familiar como a violência, a limitação de seu espaço de participação, a subordinação de sua opinião e de suas vontades às do adulto etc. Consequentemente, muitas crianças acabam sendo prejudicadas em seu desenvolvimento devido às adversidades do meio. Portanto, emergem as seguintes perguntas de pesquisa: A bolsa amarela representa o desenvolvimento infantil em meio a esse contexto adverso? Haveria por parte da narração um processo que possibilite a resolução dos problemas da criança na obra e, por meio dela, da criança leitora da obra?

Desse modo, o objetivo do presente trabalho consiste em analisar o processo de desenvolvimento da criança em A bolsa amarela, bem como o processo de reação estética do leitor. Para tanto, têm os seguintes objetivos específicos: compor o referencial teórico aportado na Psicologia da arte e na teoria da narrativa e do romance; explorar os cronotopos e sua funcionalidade na obra; compreender a estrutura da reação estética do leitor.

O presente trabalho está organizado da seguinte maneira: no item de metodologia, apresentam-se o corpus de análise, o método objetivamente analítico, desenvolvido por Vygotsky (1999) e os processos metodológicos desenvolvidos no caso da análise de $A$ bolsa amarela; na seção sobre aportes teóricos são expostos os estudos de Lev Semionovitch Vygotsky (1999), sobre a análise da reação estética, Brait Brait (1987) e Candida Vilares Gancho (2004), sobre a teoria da narrativa; e Mikhail Bakhtin (2014), sobre o cronotopo no romance. Na parte de análise, explora-se a construção dos cronotopos do romance, bem como analisa-se o sistema de estímulos fornecido ao leitor para recriar o sistema de respostas estéticas, a fim de demonstrar o processo de desenvolvimento de Raquel e a reação estética do leitor. Por fim, são tecidas breves considerações finais sobre o desenvolvimento da narradora protagonista e sobre a reação estética a qual o leitor é 
levado a experimentar durante a leitura da obra.

\section{Metodologia}

O presente trabalho toma como corpus para a análise o romance infantojuvenil $A$ bolsa amarela, da escritora brasileira Lygia Bojunga Nunes, publicado em 1976. A narrativa verbo-visual possui 135 páginas, que estão organizadas em dez capítulos: "As vontades", "A bolsa amarela", "O galo", "História do Alfinete de Fralda", "A volta da escola", "O almoço", "Terrível vai embora", "História de um galo de briga e de um carretel de linha forte", "Comecei a pensar diferente" e "Na praia".

Segundo o método objetivamente analítico, utilizado por Vygotsky (1999), o estudo em psicologia da arte deve estar focalizado na própria materialidade da obra de arte. Nas palavras do autor, para a análise em psicologia da arte "é necessário tomar por base não o autor e o espectador, mas a própria obra de arte" (VYGOTSKY, 1999, p. 25), isso porque, a obra literária é "um sistema de estímulos, organizados consciente e deliberadamente com vistas a suscitar respostas estéticas" (VYGOTSKY, 1999, p. 25). Portanto, Vygotsky (1999) expressa o método objetivamente analítico na seguinte fórmula: "da forma da obra de arte, passando pela análise funcional dos seus elementos e da estrutura, para a recriação da resposta estética e o estabelecimento de suas leis gerais" (1999, p. 27).

A primeira etapa deste estudo consistiu em compreender a aplicação do método objetivamente analítico nos estudos de Vygotsky (1999), a novela (conto) e as leis gerais da reação estética, bem como as teorias sobre a tipologia narrativa em Brait (1987) e Gancho (2004) e o gênero romance em Bakhtin (2014), visando compor o referencial teórico para análise, subsequente, de $A$ bolsa amarela.

Na segunda etapa do trabalho, apoiando-se no estudo detalhado da estrutura de $A$ bolsa amarela, analisou-se os cronotopos do romance: verificando de que forma estes foram consolidados e qual a contribuição para o efeito estético do leitor. Na terceira etapa do trabalho, observou-se a criação e solubilidade de tensões da obra, por meio dos conflitos e das tentativas de resolução dos conflitos até o clímax.

A última etapa da análise consistiu em compreender o desenvolvimento da criança e recriar, com base nos estímulos da etapa anterior, o sistema de resposta estética no leitor. Assim, por meio da elevação da tensão ou da solubilidade da tensão, na obra, compreendeu-se o desenvolvimento de Raquel e recriou-se o processo de desenvolvimento da catarse do leitor. No item a seguir, são discutidas as bases teóricas para a análise de $A$ bolsa amarela.

\section{Reação estética}

Vygotsky (1999) ao analisar o conto "Leve alento", de Iván Búnin, percebe que ele tematiza os fatos da vida da personagem Ólia Mieschérskaia e dos personagens secundários do conto. A lei geral da reação estética, no conto, parte do princípio da contradição entre fábula e enredo. No qual, a fábula seria o que o "poeta usou como já pronto - relações do dia a dia, histórias, casos, o ambiente [...] tudo que existe antes da 
narração e pode existir fora e independente dela" (VYGOTSKY, 1999, p. 177). Enquanto que o enredo é definido como "a disposição desse material segundo as leis da construção artística" (VYGOTSKY, 1999, p. 177).

Segundo Vygotsky (1999), para a arte verbal, o fator de maior importância é a sua elaboração, isto é, "a disposição dos acontecimentos na narração, o modo como o poeta leva a sua fábula ao conhecimento do leitor e a composição de sua obra" (1999, p. 179). Desse modo, a apreensão da ordem dos acontecimentos narrados se torna fundamental, a saber, se seguem a linha do tempo, ou desenvolvem-se em curva, recuando na linha cronológica (VYGOTSKY, 1999).

Vygotsky (1999) explica que "se algum movimento psicológico esbarra em um obstáculo, a nossa tensão começa a elevar-se justamente onde encontramos o obstáculo" (1999, p. 192). Assim, a carga de tensão, a cada obstáculo não superado, é somada à carga de um novo obstáculo ou dissipada na sua superação. Portanto, por meio dos procedimentos de elaboração, o autor pode criar conflitos e gerar tensões e/ ou solucionar conflitos e suavizar as tensões no plano da narrativa a tal ponto de inverter a própria intenção da fábula.

Para o autor, o artista "quando dificulta artificialmente o desenrolar da ação, excitada a nossa curiosidade, joga com as nossas conjecturas, leva-nos a desdobrar a nossa atenção" (VYGOTSKY, 1999, p. 256). Assim, a reação estética é um processo no qual se destrói energia nervosa "lembrando mais uma explosão" (VYGOTSKY, 1999, p. 257).

Desse modo, o "prazer artístico não é mera recepção, mas requer uma elevadíssima atividade do psiquismo" (VYGOTSKY, 1999, p. 258). Vygotsky (1999) explica que a emoção ao se apoiar na imaginação "se reflete numa série de representações e imagens fantásticas, que fazem as vezes de uma segunda expressão" (1999, p. 264).

As vivências fantásticas e irreais dos seres humanos, como afirma o autor, "transcorrem, no fundo, numa base emocional absolutamente real" (VYGOTSKY, 1999, p. 264). Por isso, Vygotsky (1999) considera "a fantasia como expressão central da reação emocional" (1999, p. 264). Segundo o autor, o "traço distintivo da emoção estética é precisamente a retenção de sua manifestação externa, enquanto conserva ao mesmo tempo uma força excepcional. [...] As emoções da arte são emoções inteligentes" (VYGOTSKY, 1999, p. 267), por se realizarem no córtex cerebral pela fantasia.

Vygotsky (1999) demonstrou que "toda a obra de arte [...] encerra forçosamente uma contradição emocional, suscita séries de sentimentos opostos entre si e provoca seu curtocircuito e destruição" (1999, p. 269). A esse efeito particular da obra, de destruição da luta dos sentimentos opostos, denominou catarse, definida como uma "complexa transformação dos sentimentos" (VYGOTSKY, 1999, p. 270). Desse modo, o efeito estético se encerra na catarse, ou seja, "nessa transformação do sentimento, nessa sua autocombustão, nessa reação explosiva que acarreta a descarga das emoções imediatamente suscitadas" (VYGOTSKY, 1999, p. 272). 


\section{Teoria da narrativa}

Para empreender a análise de $A$ bolsa amarela, buscou-se compreender as principais características da tipologia narrativa. Portando, a seguir, apresentam-se os estudos Gancho (2004) e Brait (1987).

Gancho (2004) explica que o gênero romance "é uma narrativa longa, que habitualmente envolve um número considerável de personagens [...] maior número de conflitos, tempo e espaço mais dilatados" (2004, p. 9). Importante ressaltar que o romance é um dos "tipos relativamente estáveis de enunciados" (BAKHTIN, 2016, p. 12). O romance como um gênero secundário (complexo), segundo Bakhtin (2016), no processo de sua formação histórica incorporou e reelaborou "diversos gêneros primários (simples) que se formaram nas condições da comunicação discursiva imediata" (2016, p. 15).

Primeiramente, deve-se entender o que é enredo, pois, diferentemente, da definição de Vygotsky (1999), para Gancho (2004) ele corresponde ao "conjunto dos fatos de uma história" (2004, p. 11). Para organizar, logicamente, um romance, o enredo é elaborado com diversos conflitos. Gancho (2004) define o conflito como sendo "qualquer componente da história (personagens, fatos, ambiente, ideias, emoções) que se opõe a outro, criando uma tensão que organiza os fatos da história e prende a atenção do leitor" (2004, p. 13). Portanto, são os conflitos narrativos que "determinam as partes do enredo" (2004, p. 13), sendo elas: "exposição", "complicação", "clímax" e "desfecho" (2004, p. 13-14).

A exposição, segundo Gancho (2004), tem por objetivo situar o leitor no que se seguirá. Portanto, apresenta as personagens, o tempo e o espaço narrativo (2004, p. 13). Diferentemente, a complicação é o desenvolvimento da narrativa, correspondendo ao local dos conflitos narrativos. Segundo Gancho (2004), é na complicação que "agem as forças auxiliares e opositoras ao desejo da personagem e que intensificam o conflito" (2004, p. 13). O clímax corresponde ao "momento de maior tensão, no qual o conflito chega a seu ponto máximo" (GANCHO, 2004, p. 14). Enquanto que o desfecho corresponde à última parte do enredo e se caracteriza pela "solução dos conflitos, boa ou má" (2004, p. 14).

Compreendido o processo de organização do romance, adentra-se ao estudo dos personagens. Gancho (2004) apresenta que "a personagem é um ser fictício responsável pelo desempenho do enredo; em outras palavras é quem faz a ação" (2004, p. 17). Brait (1987) afirma que o autor de uma narrativa "recorre aos artifícios oferecidos por um código a fim de engendrar suas criaturas" (1987, p. 52). Portanto, para construir a materialidade particular desses seres deve articular "um jogo de linguagem que torne tangível a sua presença e sensíveis os seus movimentos" (1987, p. 52).

Brait (1987) descreve dois tipos de personagens da narrativa: as planas e as redondas. As personagens planas "são construídas ao redor de uma única ideia ou qualidade, [...] estão imunes à evolução no decorrer da narrativa” (1987, p. 40-41). Já as personagens redondas são "definidas por sua complexidade, apresentando várias qualidades ou tendência, surpreendendo convincentemente o leitor" (1987, p. 41). Outro aspecto importante é a definição de narrador, segundo Gancho (2004, p. 30) "o narrador 
não é autor, mas uma entidade de ficção, isto é, uma criação linguística do autor".

Por fim, para este trabalho, torna-se importante a discussão dos conceitos de tempo cronológico e de tempo psicológico. No primeiro caso, o tempo "transcorre na ordem natural dos fatos [...] do começo até o final" (GANCHO, 2004, p. 25). No segundo, o tempo "transcorre numa ordem determinada pelo desejo ou pela imaginação do narrador ou das personagens, isto é, altera a ordem natural dos acontecimentos" (GANCHO, 2004, p. 25). A seguir, apresenta-se os estudos de Bakhtin (2014) sobre os cronotopos do romance.

\section{Cronotopos: tempo e espaço na teoria de Bakhtin}

Para Bakhtin (2014) a literatura assimilou e incorporou para si "os aspectos isolados de tempo e de espaço acessíveis em dado estágio histórico do desenvolvimento da humanidade" (2014, p. 211). Portanto, "no cronotopo artístico-literário ocorre a fusão dos indícios espaciais e temporais num todo compreensível e concreto" (BAKHTIN, 2014, p. 211). Nesse cronotopo "o tempo condensa-se, comprime-se, torna-se artisticamente visível; o próprio espaço intensifica-se, penetra no movimento do tempo, do enredo e da história" (BAKHTIN, 2014, p. 211).

Para Bakhtin (2014) "todas as definições espaço-temporais são inseparáveis umas das outras e são sempre tingidas de um tom emocional” (2014, p. 349). É no cronotopo que "o tempo adquire um caráter sensível concreto; no cronotopo, os acontecimentos do enredo se concretizam, ganham corpo e enchem-se" (BAKHTIN, 2014, p. 355). Ainda, o cronotopo tem função organizadora, segundo Bakhtin (2014, p. 355-256) "Todos os elementos abstratos do romance [...] gravitam ao redor do cronotopo, graças ao qual se enchem de carne e sangue".

Embora Bakhtin (2014) não se detenha à análise do ouvinte-leitor, em sua complexidade, ou seja, sobre "sua posição cronotópica e seu papel de renovador da obra" (2014, p. 361), ele afirma que "toda obra literária é dirigida para fora de si, para o ouvinteleitor e, em certa medida, antecipa suas possíveis reações” (2014, p. 361). Assim, com base nos aportes teóricos, a seguir, encaminha-se a análise do processo de desenvolvimento de Raquel no romance, bem como a reação estética do leitor, diante da leitura d'A bolsa amarela. Desse modo, serão analisados os cronotopos e a estrutura da reação estética do leitor.

\section{Os cronotopos d'A Bolsa Amarela}

Na sua narração, Raquel escolhe fatos da sua experiência subjetiva para contar ao leitor a sua história. Assim, inicia com a afirmação, no presente: "Eu tenho que achar um lugar pra esconder as minhas vontades" (NUNES, 2012, p. 9). Na sequência, conta ao leitor que possui três grandes vontades: vontade de crescer, vontade de ser menino e vontade de escrever (NUNES, 2012). Com base nisso, pode-se iniciar a análise dos cronotopos $d$ 'A bolsa amarela.

Raquel relata ao leitor a seguinte situação sobre as vontades: "já fiz de tudo pra me livrar delas. Adiantou? Hmm! É só me distrair um pouco e uma aparece logo. Ontem mesmo 
[...] pensei: puxa vida, falta tanto tempo pra ser grande. Pronto: a vontade de crescer desatou a engordar [...]" (NUNES, 2012, p. 10). Nesse trecho, apresenta-se a relação conflituosa de Raquel com sua vontade de crescer: manifestada, por meio do pensamento, a contrapartida da realidade: "falta muito tempo pra ser grande", Raquel sente sua vontade de crescer "engordar" dentro dela.

Na sequência, a menina conta sobre o surgimento da sua vontade de escrever: "Um dia fiquei pensando o que é que eu ia ser mais tarde. Resolvi que eu ia ser escritora. Então já fui fingindo que era" (NUNES, 2012, p. 10). Novamente, o mecanismo do pensamento articula a relação da vontade de escrever e a realidade. Devido ao fato de Raquel não ser adulta ela apenas pode fingir que é escritora.

Por conta do desdobramento do "fingimento" de Raquel, o leitor compreende o problema relacionado com a vontade de ser menino, após o irmão descobrir suas cartas inventadas para André e desacreditar sobre a história contada pela menina, Raquel tenta argumentar que escolheu inventar um amigo menino porque: "é muito melhor ser homem do que mulher [...]. Olha: lá na escola, quando a gente tem que escolher um chefe pras brincadeiras, ele sempre é um garoto" (NUNES, 2012, p. 16). Mais uma vez, a vontade de Raquel se apresenta como conflitante com a situação concreta vivenciada por ela, pois percebe que por ser menina está em uma situação social desvantajosa, mantendo dentro de si a vontade de ser menino.

Portanto, percebe-se que as vontades constituem o plano psíquico da menina, pelo emprego de um tempo controlado por Raquel, consolidando um dos cronotopos da narrativa: o cronotopo da imaginação, caracterizado pela articulação das vontades de Raquel. Paralelamente, como pode ser visto nos trechos recortados, materializa-se o outro cronotopo: o cronotopo da realidade, marcado pelas adversidades de Raquel, no qual o tempo é controlado pelo exterior: pais, irmãos e a escola.

Percebe-se que embora sejam opostos em sua elaboração: interno-externo, subjetivosocial, eles estão continuamente em relação. O plano da realidade apresenta uma dificuldade, logo Raquel articula algo no plano da imaginação, como resultado ou tentativa de solucionar tal problema. No entanto, essa articulação interna criativa, por vezes, gera um novo problema no cronotopo da realidade. Portanto, torna-se importante analisar a articulação desses dois cronotopos na narrativa.

Toma-se, primeiramente, o capítulo "A bolsa amarela". Nesse capítulo, Raquel conta como conseguiu a bolsa amarela, que surge como um lugar para a menina esconder os seus segredos. Embora, esteja no plano da realidade a bolsa dá suporte ao plano da imaginação, pois passa a abrigar as vontades de Raquel e suas histórias.

A partir desse capítulo, Raquel torna-se inseparável da bolsa amarela e, por meio dela, retoma alguns dos pontos interrompidos no plano da realidade, antes da bolsa. É o caso do romance do galo Rei, que foi rasgado pela menina após os familiares rirem da narrativa. Devido a essa adversidade, no plano da realidade, a menina diz: "resolvi que até o dia de ser grande não escrevia mais nada. Só dever da escola e olhe lá" (NUNES, 2012, 
p. 23). Entretanto, na manhã seguinte à aquisição da bolsa, Raquel passa a abrigar histórias dentro da bolsa, a primeira delas foi a história que tinha sido rasgada. Assim, a menina recriou várias situações posteriores à história do galo Rei, inclusive mudou seu nome para Afonso.

Entretanto, as adversidades do plano da realidade continuam acontecendo, o mecanismo da bolsa tem a função de suavizar os conflitos da realidade no plano da imaginação, mas não são resolvidos por completo. É o caso do capítulo "a volta da escola". Raquel contou que saiu da escola com a bolsa pesadíssima, devido ao fato de não ter terminado a redação sobre o presente que queria ganhar. Por esse problema, no plano da realidade, Raquel, no retorno para casa, faz incursões pelo plano da imaginação.

Assim, um novo personagem é criado: a Guarda-Chuva - denominação escolhida pela personagem. Afonso, personagem que a encontrou, relata alguns fatos da vida da personagem, até um determinado ponto, visto que, dali para frete, toda a história estava enguiçada. Assim, percebe-se que o pouco que a menina consegue criar permanece com a mesma adversidade da história de Raquel na escola, isto é, enguiçada.

O plano da realidade permanece, continuamente, fornecendo adversidades, por vezes Raquel consegue contorná-los no plano da imaginação, caso do galo rei, mas por outras apenas suaviza uma parte do conflito. Encontra um guarda-chuva, mas não consegue desenguiçar a sua história. Isso demonstra que Raquel ainda não consolidou o cronotopo da imaginação como um lugar pleno de suas realizações, mas está em processo de atingilo.

Outra personagem criada foi o galo de briga Terrível. Raquel contou que ele estava perdendo todas as lutas contra um galo mais jovem, tal qual ela vinha perdendo as suas lutas com a realidade. Raquel e Afonso, vendo que o amigo seria destruído na próxima luta, armam um plano e o prendem na bolsa amarela. Esse capítulo termina com Raquel comentando: "Mas que peso, puxa vida!" (NUNES, 2012, p. 64).

O que materializa a narração de Raquel é o contínuo entrelaçamento do cronotopo da imaginação com o cronotopo da realidade, a experiência subjetiva de Raquel ganha corpo nesses dois planos: por meio dos recortes da vivência da realidade conflituosa e da apreensão e recriação da realidade na imaginação. Esse processo é exemplar no capítulo "O Almoço".

Raquel, começa por apresentar que a família iria a um almoço na casa da tia Brunilda. A partir disso, descreveu uma série de adversidades no plano da realidade que enfrentou antes de sair de casa, bem como a consequência disso: "sai de casa achando a minha vida o fim" (NUNES, 2012, p. 67).

O capítulo segue com outras adversidades, que obrigam a menina a fugir para o quintal. Longe dos adultos, ela conversa com suas personagens, resolvendo alguns dos conflitos da bolsa: "Abri a bolsa. Era o Terrível, coitado. Tanto seguraram o bico dele pra não abrir [...] que ele resolveu ter uma crise de soluço [...]. Soluçou meia hora" (NUNES, 2012, p. 72). Quando voltou para o almoço, enfrentou outro problema: mesmo não gostando 
de bacalhoada teve de comer o prato, gerando, assim, mais um conflito.

Na sequência, o Alberto, filho da tia Brunilda, observou a bolsa da menina e disse: "[...] vocês já viram o tamanho da bolsa de Raquel?" (NUNES, 2012, p. 73), pondo em evidência, justamente, o que Raquel queria manter escondido. Alberto ainda criou o versinho "Vou espiar essa bolsa para ver o que é que ela tem" (NUNES, 2012, p. 74) e repetiu-o, incessantemente, para importunar Raquel.

Inicialmente, a menina tentou mudar de assunto, mas ele repetiu a música. Como nada parecia resolver, Raquel enfrentou a situação, dizendo: "A senhora [tia Brunilda] acha engraçado tudo que o Alberto faz, não é?" (NUNES, 2012, p. 75). A partir desse posicionamento, toda a família se voltou contra Raquel, instaurando-se uma discussão, na qual a menina participou ativamente, diz ela: "Mas aconteceu uma coisa esquisita: eu não podia parar de falar" (NUNES, 2012, p. 76).

Entretanto, para reestabelecer o controle dos adultos, a irmã deu-lhe um beliscão, silenciando a voz da menina. Nesse momento, Alberto conseguiu alcançar a bolsa e os dois entraram em uma luta pelo objeto. Novamente, Raquel perdeu, então, conta ao leitor "Eu quis falar. Trancou tudo na garganta. Me lembrei do fecho. Pensei com toda a força pra ver se ele ouvia: 'Enguiça'” (NUNES, 2012, p. 76). Devido ao fato de Raquel ter perdido no plano da realidade, a saída foi recorrer ao plano da imaginação, marcado pelo uso de dois verbos caraterísticos da atividade mental: lembrar e pensar.

A partir desse fato, Raquel entrelaça com maior intensidade os cronotopos real e imaginário, por vezes misturando-os. Para apreender essa questão deve-se acompanhar os fatos apresentados por Raquel, diz a menina: "Puxa vida, por que é que eu não tinha nascido Alberto em vez de Raquel [...] a vontade de ter nascido menino deu uma engordada tão grande que acordou o Terrível, [...] a bolsa desatou a dar pinote no chão" (NUNES, 2012, p. 76-77). Percebe-se que nesse ponto, Raquel não se posiciona em um único cronotopo, mas migra entre ambos, mesclando-os. Raquel traz os fatos do plano da imaginação para a realidade, a bolsa dá "pinotes".

As vontades vão crescendo no plano da imaginação e a bolsa continua sendo violada pelos familiares no plano da realidade. O excesso de tensão provocado pelas adversidades faz com que Raquel apresente ao leitor uma junção dos dois cronotopos, diz a menina: "De repente, deu um estouro danado [...] todo mundo pulou para trás. E aí deu outro estouro. [...] o Alberto então pegou ela pra abrir. E o fecho [....] abriu!" (NUNES, 2012, p. 79).

Quando a bolsa é aberta consolida-se a perda de Raquel no plano da realidade, que já vinha sendo articulada, e culminou na fusão dos cronotopos, no estouro das vontades de Raquel. Assim, com a bolsa aberta, Raquel se concentra sobre o plano da imaginação: "O Afonso pulou pra fora. Mascarado. Agarrando o Terrível com força. O Terrível tava um bocado esquisito: bico, asa, pata, tava tudo amarrado" (NUNES, 2012, p. 79).

Nesse sentido, Raquel retira o foco do leitor do plano da realidade, recontando seu estado de ânimo por meio do Terrível: Raquel tal qual sua personagem estava amarrada em todos os sentidos pela opressão dos familiares. Devido a isso, o plano da realidade, a 
partir desse ponto, se torna menos presente na narração de Raquel. Vale destacar a última menção deste, no capítulo, Raquel diz: "O pessoal espiou dentro da bolsa" (NUNES, 2012, p. 80), porém, logo a seguir, retorna ao plano da imaginação "Espiei também. Lá bem no fundo vi uns restos de vontade, assim que nem resto de balão quando estoura. Mas só eu que vi mais ninguém" (NUNES, 2012, p. 80).

Percebe-se que a situação na casa da tia Brunilda é um marco no processo de desenvolvimento de Raquel: pela primeira vez ela embate a opressão da família e, embora, tenha perdido no plano da realidade, emocionalmente, ela teve um ganho e encontrou a saída no plano da imaginação para os seus problemas.

Portanto, a luta incessante entre os cronotopos da realidade e da imaginação encaminha ao clímax do romance, onde há a fusão desses dois cronotopos. Raquel ao perder a luta na realidade e gerar a fusão dos cronotopos, no estouro das vontades dentro da bolsa, passa a se posicionar no cronotopo da imaginação-realidade. Assim, cria a história de Terrível, na qual a Guarda-Chuva viu ele perder a luta contra seu oponente. Porém, a partir da reflexão de sua própria criação, Raquel teve um curto-circuito e fala para Afonso: "Você acha que se não tivessem costurado o pensamento do Terrível com a tal linha forte ele tinha vindo aqui brigar?" (NUNES, 2012, p. 91).

Essa tomada de consciência de Raquel, no plano da imaginação-realidade, transforma o próprio modo da menina se perceber, avançando em seus obstáculos, a menina diz: "Eu tinha dito que nunca mais na vida, até ser grande, eu escrevia outro romance. Mas aquele negócio que aconteceu com o Terrível me deixou tão- sei lá- tão diferente [...]" (NUNES, 2012, p. 92).

Assim, Raquel se propõem a recriar a história do Terrível aportada na sua reflexão do pensamento costurado, recriando um final feliz. Raquel conta que os donos de Terrível costuraram o pensamento dele com uma linha forte e que, por toda a vida, ele só pensou em brigada e vencer. Porém, na última briga dele: "Quanto mais o Terrível apanhava, mais força ela [a linha] fazia. Mais força. Mais força. Até que de repente - plá!!- de tanto fazer força rebentou" (NUNES, 2012, p. 100).

Portanto, percebe-se que, novamente, Raquel reconstrói a situação na casa da tia Brunilda, porém agora demonstra a vitória que ela teve no plano da imaginação-realidade: "[...] o pensamento do Terrível descosturou [...], e ele desatou a pensar mil coisas, ficou até tonto de tanto pensamento junto [...] pensou logo: besteira eu morrer nessa praia só porque eles cismaram que eu tenho que brigar [...]. E se mandou! Correu pro mar" (NUNES, 2012, p. 100). O que se apresenta aqui, é o próprio pensamento descosturado de Raquel, ao colocar o cronotopo da imaginação-realidade em primeiro plano percebe que sua vitória se encontra, justamente, nesse ambiente, e por ali segue narrando sua experiência.

Isso se torna evidente nos três últimos capítulos, visto que os fatos recortados para o leitor se constituem, na grande maioria, de imersões no plano da imaginação-realidade. Assim, Raquel constrói um estado de ânimo positivo, comparando-se aos sete primeiros capítulos. Raquel afirma, no último capítulo: "Minha semana de castigo foi ótima: escrevi à 
vontade - tudo que passava na minha cabeça e tudo que acontecia na bolsa amarela. [...] E eu fiquei pensando que fazia uma bruta diferença a gente ter amigo" (NUNES, 2012, p. 125). Tudo que Raquel enuncia ao leitor, suas criações no plano da imaginação-realidade, dão suporte ao seu desenvolvimento, ela descobriu na relação com suas personagens que havia um espaço no qual ela e seu modo de ver o mundo poderiam existir.

Ela comenta: "Minha vida foi melhorando. Eu já não inventava muita coisa, meu pessoal não ficava tão contra mim" (NUNES, 2012, p. 125). Nesse trecho, percebe-se que, ainda, os pais ficavam contra ela, mas que apesar disso as coisas foram "melhorando". Importante ressaltar que não se estabelece um parâmetro para não inventar muita coisa (NUNES, 2012).

Na sequência do último capítulo, apresenta-se a mesma inventividade com as personagens fictícias de Raquel. Ela sai de casa para empinar pipa com as vontades para deixá-las irem embora; ela leva Afonso e a Guarda-Chuva que também acabam se despedindo da menina e ao final sobra, apenas, o alfinete na bolsa e ela conclui: "A bolsa amarela tava vazia à beça. Tão leve. E eu também, gozado, eu também estava me sentindo um bocado leve" (NUNES, 2012, p. 135).

Percorrido a análise dos cronotopos, desde sua manifestação, entrelaçamento, fusão na catarse, e a criação do cronotopo da imaginação-realidade, têm-se condições para avançar à análise do desenvolvimento de Raquel e de seu leitor infantil. Assim, a seguir, encaminha-se o estudo, paralelamente, do desenvolvimento de Raquel e da reação estética do leitor d'A bolsa amarela.

\section{O desenvolvimento de Raquel e a reação estética do leitor}

Inicialmente, ressalta-se que a análise dos cronotopos foi a base para se perceber o desenvolvimento de Raquel e a reação estética do leitor e que alguns aspectos já foram abordados, superficialmente, no item anterior. Portanto, desse momento em diante, serão analisados apenas os dois momentos efetivamente prototípicos da narração da menina na questão do desenvolvimento e da reação estética.

O primeiro caso prototípico foi narrado por Raquel no capítulo "A volta da escola". Como já foi apresentado, a professora solicitou uma produção textual e Raquel não teve tempo de terminá-la, isso causou o aumento do peso dentro da bolsa, ou seja, um acúmulo de tensão em Raquel. Como apresenta Vygotsky (1999), a cada obstáculo não superado soma-se uma nova carga à tensão já existente. Assim, o que vêm acontecendo com Raquel também acontece com o leitor. Cada conflito não superado por Raquel acumula tensões no leitor.

Portanto, quando Raquel se propõem a continuar contando sobre a Guarda-Chuva, por meio de Afonso, o leitor vai acompanhando a tentativa de Raquel, que a cada fracasso seu, soma uma tensão à psique do leitor. Da mesma forma, quando Afonso vê o Terrível, o fato de o galo não querer perder nenhuma briga e ao mesmo tempo não ter condição de ganhar na próxima luta é um conflito intransponível. Assim, nesse momento do processo de desenvolvimento de Raquel, suas tentativas de solucionar o plano da realidade, por meio 
do plano da imaginação, fracassam. E não é só ela quem fica com a bolsa pesadíssima, mas também seu leitor.

A luta entre o cronotopo da imaginação e o cronotopo da realidade é constante, vencendo sempre o plano da realidade. Isso continua se manifestando no capítulo "O almoço", o segundo caso prototípico tomado para a análise. Ressalta-se que não houve nenhuma resolução às adversidades de Raquel, assim, o leitor inicia o capítulo com o mesmo estado de tensão, anteriormente, analisado.

Raquel, nesse capítulo, está se arrumando para ir ao almoço da casa da tia Brunilda. Como já foi descrito, uma série de adversidades acontecem à menina. Cada um dos problemas é um conflito, isto é, um obstáculo barrando a ação da menina. Assim, o leitor já com uma carga considerável de tensão acrescenta mais algumas ao si mesmo, e quando Raquel sai para o almoço, o leitor está, justamente, se sentido pesado como Raquel.

Este percurso de sucessivas vitórias das adversidades sobre as tentativas de Raquel, se agrava com a chegada na casa da tia Brunilda, fazendo-a fugir para o plano da imaginação - ouve soluços vindo de dentro da bolsa amarela. O tempo sozinha com suas personagens fez com que ela criasse uma solução no plano da imaginação: a cura do soluço do Terrível, por isso que, quando voltou à mesa, sentiu-se melhor. Portanto, percebe-se uma certa suavização da realidade por parte do plano da imaginação, o leitor acompanhando o processo narrativo é levado a diluir uma tensão criada por Raquel no plano da imaginação.

Entretanto, à mesa, uma série de adversidades são apresentadas, à cada conflito se soma uma tensão à narração de Raquel e à reação estética do leitor da obra. A discussão com os familiares, que a obrigaram a comer a bacalhoada, soma ainda mais tensão. E, quando Raquel inicia o enfrentamento à tia Brunilda, sobre o Alberto, tanto ela como o leitor são uma "bomba relógio", qualquer tensão que se some pode ocasionar uma "explosão".

Assim, na luta pela bolsa, Raquel vai encaminhando o leitor ao clímax do romance, a cada tentativa fracassada de Raquel é somada uma tensão ao seu problema e uma tensão ao seu leitor, até o ponto em que Raquel, com suas vontades enchendo como balão, resolve estourá-la dentro da bolsa e se abrigar no plano da imaginação. Como já foi dito, Raquel passa a misturar os cronotopos até o pondo em que os funde no curto-circuito, no qual ocorre a criação de um novo cronotopo: o plano da imaginação-realidade, fazendo com que a menina vença a seu modo.

Raquel, ao fugir para o plano da imaginação-realidade e permanecer por lá, durante a narração dos últimos capítulos, cria conflitos e aos poucos os supera, fazendo o caso oposto que vinha se propondo nos capítulos iniciais. O leitor, a partir desse momento, passa a dissipar a energia acumulada, não armazenando todo aquele conjunto de tensões. Assim, quando Raquel cria a luta do Terrível e lhe dá um final trágico na briga, ao passo que ela cria uma tensão no leitor, logo em seguida, ao refletir sobre sua própria história no almoço, reescreve a história de Terrível, dando-lhe um final feliz, solucionando a tensão acumulada.

Portanto, o segundo caso prototípico demonstra o desenvolvimento de Raquel. 
Embora ela não tenha conseguido se livrar das três vontades para sempre, visto que inicia o romance no presente da enunciação, com as três vontades, e termina o romance, no passado da enunciação, empinando as vontades até sumirem, pode-se afirmar que houve, no processo da narração, um desenvolvimento emocional de Raquel. Não se pode afirmar que a Raquel do capítulo "Volta da escola" é a mesma de "Na praia", último capítulo do romance.

Assim, Raquel não se desfez, efetivamente, das vontades. No plano da imaginaçãorealidade criou uma situação, dado seu desenvolvimento emocional, na qual as vontades não Ihe são mais um incômodo e as liberta na praia. Tudo é um efeito peculiar causado pela narração de Raquel. Assim, a menina encaminha o seu leitor a vivenciar um estado positivo ao final do romance, mas que não corresponde perfeitamente o seu estado no presente da enunciação.

Desse modo, ao final do romance, embora que no percurso narrativo tenha acumulado inúmeras tensões, o leitor de Raquel não percebe que a narradora não está no presente soltando suas vontades, mas por perceber apenas o cronotopo da imaginação-realidade, sente-se leve como a bolsa amarela. Todas as suas tensões, de uma forma ou de outra, foram dissipadas pelo processo narrativo de Raquel. Portanto, Raquel encaminhou o leitor a um estado de ânimo peculiar de suavização das tensões nos três últimos capítulos do romance.

\section{Considerações finais}

Diante do que foi percorrido, retoma-se o objetivo geral do presente trabalho: analisar o processo de desenvolvimento da criança em A bolsa Amarela, bem como o processo de reação estética do leitor. Para tanto, buscou-se apresentar e discutir os estudos de Vygotsky (1999), sobre a análise da reação estética, Brait (1987) e Gancho (2004), sobre a teoria da narrativa; e Bakhtin (2014), sobre o cronotopo no romance.

$\mathrm{Na}$ sequência, com a análise dos cronotopos do romance, foram percebidos dois cronotopos de natureza oposta: o cronotopo da realidade e o cronotopo da imaginação, que foram articulados no processo narrativo de Raquel. O primeiro é marcado pelas adversidades de Raquel na família e o segundo pelas tentativas de superação das adversidades da menina no plano da imaginação. Percorreu-se a relação desses dois cronotopos até o clímax do romance, isto é, à fusão dos cronotopos, no qual a perda de Raquel no plano da realidade faz com que ela funda os dois cronotopos, permanecendo no plano da imaginação-realidade.

Com base no estudo dos cronotopos, pode-se compreender toda a narração de Raquel. Assim, avançou-se para a análise dos estímulos da obra, tomando-se dois momentos prototípicos "A volta da escola" e "O almoço". No primeiro momento, descreveuse o processo de acúmulo de tensão por meio de obstáculos não superados pela menina. No segundo caso, percorreu-se o processo de acúmulo de tensão até o clímax, que gerou a explosão das vontades de Raquel no curto-circuito. O processo de fusão do plano da imaginação e do plano da realidade iniciou a recriação da realidade no plano da 
imaginação, o que ocasionou a dissolução das tensões do plano da realidade.

Portanto, como já foi descrito, o leitor d'A bolsa amarela está percorrendo os sucessivos fracassos de Raquel e, a cada obstáculo que sua leitura esbarra, ele acrescenta uma carga de tensão em si mesmo. Portanto, percebe-se que, até o capítulo "O almoço", o leitor acrescenta tensões à sua psique sem sucesso em dissipar a energia psíquica acumulada. Entretanto, na briga de Raquel com a família, quando Alberto toma a bolsa e todos começam a tentar abri-la, Raquel sem poder reagir no plano da realidade, fugindo para o plano da imaginação, estoura as suas vontades em um curto-circuito, e, a partir deste momento, passa a criar suas próprias soluções para seus problemas no plano da imaginação-realidade. Esse processo, passa a dissipar a energia psíquica acumulada, causando um estado de ânimo positivo ao final da leitura do romance.

Desse modo, o processo narrativo de Raquel encaminha à compreensão de seu desenvolvimento emocional, não como superação das vontades, mas como uma suavização, por meio da criação das soluções no plano da imaginação-realidade. Como foi discutido, anteriormente, não se pode negar o desenvolvimento emocional de Raquel nos últimos capítulos do romance. Entretanto, não se pode afirmar que as vontades deixaram de existir plenamente, visto que, no presente da enunciação, Raquel possui as "três grandes vontades".

Portanto, pode-se afirmar que Raquel, por seu processo narrativo, que inverte os acontecimentos dos fatos na articulação dos cronotopos, encaminha o leitor à compreensão de um sentimento oposto ao que realmente sente no presente da enunciação. Levando-o a atingir um estado de ânimo característico a um final feliz, desenvolvendo-o emocionalmente.

\section{Referências}

BAKHTIN, Mikhail. Os gêneros do discurso. Trad. de Paulo Bezerra. São Paulo: Editora 34, 2016.

BAKHTIN, Mikhail. Questões de literatura e estética: a teoria do romance. Trad. de Aurora Fornoni Bernadini et al. 7.ed. São Paulo; Hucitec, 2014.

BRAIT, Brait. A personagem. 3. ed. São Paulo: Ática, 1987.

GANCHO, Candida Vilares. Como analisar narrativas. 8. ed. São Paulo: Ática, 2004.

NUNES, Lygia Bojunga. A bolsa Amarela. 35. ed. 23. reimpr. Rio de Janeiro: Casa Lygia Bojunga, 2012.

RECHOU, Blanca-Ana Roig. Da literatura para a infância à literatura de fronteira: Agustín Fernandéz Paz e Lygia Bojunga. Estudos de Literatura Brasileira Contemporânea, Brasília, n. 36, p. 153-171, jul.-dez. 2010. Disponível em: http://periodicos.unb.br/index.php/estudos/article/viewArticle/2887. Acesso em: 10 mar. 2018. 
SILVA, Maria Marlene R. da. As relações sociais da criança na obra de Lygia Bojunga Nunes. Estudos de Literatura Brasileira Contemporânea, Brasília, n. 5, p. 9-13, mar. 2000. Disponível em: http://periodicos.unb.br/index.php/estudos/article/view/2534. Acesso em: 10 mar. 2018.

VYGOTSKY, Lev Semionovitch. Psicologia da Arte. São Paulo: Martins Fonte, 1999.

ZONIN, Carina Dartora. Realidade e imaginação: uma (re)descoberta do ser em narrativas lygianas. Nau Literária - Revista eletrônica de Crítica e Teoria de Literaturas, Porto Alegre, v. 4, n. 1, p. 1-21, jan./jun. 2008. Disponível em: http://seer.ufrgs.br/NauLiteraria/article/viewFile/5828/3432. Acesso em: 25 mar. 2018.

\section{NOTAS DE AUTORIA}

Géssica Aparecida Cappoani (gessicacappoani@gmail.com) é Mestre em Letras pela Universidade Tecnológica Federal do Paraná, câmpus Pato Branco. Especialista em Educação para a Infância pelas Faculdades Integradas do Vale do Ivaí. Graduada em Letras Português - Inglês pela Universidade Tecnológica Federal do Paraná, câmpus Pato Branco. Graduada em Pedagogia pela Universidade Cruzeiro do Sul. Tem experiência na área de Letras Português, com enfoque em Literatura Brasileira, bem como na área de Pedagogia, com enfoque nos processos de ensino aprendizagem na Educação Infantil.

Anselmo Pereira de Lima (anselmo@utfpr.edu.br) é Doutor e Mestre em Linguística Aplicada e Estudos da Linguagem pela Pontifícia Universidade Católica de São Paulo. Licenciado em Letras Português-Inglês pelas Faculdades Oswaldo Cruz, em São Paulo. Bacharelado em Direito em andamento no Centro Universitário Mater Dei. Professor Associado II da Universidade Tecnológica Federal do Paraná, Câmpus Pato Branco, onde atua como Professor-Pesquisador no Programa de Pós-Graduação em Letras (PPGL) e no Curso de Licenciatura em Letras Português-Inglês.

\section{Agradecimentos}

Não se aplica.

\section{Como citar esse artigo de acordo com as normas da ABNT}

CAPPOANI, Géssica Aparecida; LIMA, Anselmo Pereira de. Uma análise estética na leitura d'A bolsa amarela, de Lygia Bonjuga Nunes. Anuário de Literatura, Florianópolis, v. 26, p. 01-16, 2021.

\section{Contribuição de autoria}

Géssica Aparecida Cappoani: a contribuição da autora no artigo foi na concepção, coleta de dados e análise de dados, elaboração do manuscrito, redação, discussão de resultados.

Anselmo Pereira de Lima: a contribuição do autor no artigo foi na análise de dados, discussão de resultados e revisão final.

\section{Financiamento}

Não se aplica.

\section{Consentimento de uso de imagem}

Não se aplica

\section{Aprovação de comitê de ética em pesquisa}

Não se aplica.

\section{Conflito de interesses}

Não se aplica.

\section{Licença de uso}

Os/as autores/as cedem à Revista Anuário de Literatura os direitos exclusivos de primeira publicação, com o trabalho simultaneamente licenciado sob a Licença Creative Commons Attribution (CC BY) 4.0 International. Estra licença permite que terceiros remixem, adaptem e criem a partir do trabalho publicado, atribuindo $\mathrm{O}$ 
devido crédito de autoria e publicação inicial neste periódico. Os autores têm autorização para assumir contratos adicionais separadamente, para distribuição não exclusiva da versão do trabalho publicada neste periódico (ex.: publicar em repositório institucional, em site pessoal, publicar uma tradução, ou como capítulo de livro), com reconhecimento de autoria e publicação inicial neste periódico.

\section{Publisher}

Universidade Federal de Santa Catarina. Programa de Pós-graduação em Literatura. Publicação no Portal de Periódicos UFSC. As ideias expressadas neste artigo são de responsabilidade de seus/suas autores/as, não representando, necessariamente, a opinião dos/as editores/as ou da universidade.

\section{Histórico}

Recebido em: 02/07/2020

Aprovado em: 05/03/2021

Publicado em: 28/06/2021 